\title{
Screening and characterization of $\beta$-glucosidase production by Saccharomyces cerevisiae
}

\author{
Sasithorn Sirilun ${ }^{1}$, C. Chaiyasut ${ }^{1}$, Noppawat Pengkumsri ${ }^{1}$, Sartjin Peerajan ${ }^{2}$, Khontaros Chaiyasut ${ }^{2}$, Prasit Suwannalert ${ }^{3}$, \\ Bhagavathi Sundaram Sivamaruthi ${ }^{1 *}$ \\ ${ }^{1}$ Department of Pharmaceutical Sciences, Faculty of Pharmacy, Chiang Mai University, Chiang Mai 50200, Thailand. ${ }^{2}$ Health Innovation Institute, Chiang \\ Mai 50230, Thailand. ${ }^{3}$ Department of Pathobiology, Faculty of Science, Mahidol University, Bangkok 10400, Thailand.
}

\author{
ARTICLE INFO \\ Article history: \\ Received on: 24/11/2015 \\ Revised on: 04/12/2015 \\ Accepted on: 23/01/2016 \\ Available online: 28/05/2016 \\ Key words: \\ $\beta$-Glucosidases, Response \\ Surface Methodology, \\ S. cerevisiae, Thai fruits and \\ fruit-derived beverages.
}

\begin{abstract}
Beta-Glucosidases (BGS) are the group of hydrolase enzymes, involved in the degradation processes and many biological processes. Due to demand, intensive screening of BGS is required to explore the natural microbial source of BGS. The current study deals with isolation and identification of BGS producing S. cerevisiae from Thai fruits \& beverages and assessment of impact of $\mathrm{pH}$, temperature, and salt concentration on BGS production. About 34 samples were collected. Yeast cells were isolated by plate method and characterized. About ten different strains were isolated and identified. The strain has been confirmed as S. cerevisiae through ribosomal sequencing. The optimization of BGS production was achieved by Box-Behnken design and Response Surface Methodology and confirmed that $\mathrm{pH} 4.0$, temperature at $40{ }^{\circ} \mathrm{C}$, and $0.5 \%$ of $\mathrm{NaCl}$ are optimum conditions. The kinetic analysis suggested that $24 \mathrm{~h}$ of incubation achieve the maximum yield. The reported $S$. cerevisiae strain could be the safer source for BGS. Further studies on enzyme recovery and purification will unbolt the way to attain high-quality microbial enzyme.
\end{abstract}

\section{INTRODUCTION}

Beta-Glucosidases ( $\beta$-D-glucoside glucohydrolases; EC3.2.1.21) (BGS) are the group of heterogeneous glycoside hydrolase enzymes that can break the $\beta$-glucosidic linkages of both disaccharide and oligosaccharide or either of them and other conjugates of glucose. Glucosidases are involved in the degradation process of cellulosic biomass, glycolipids, cyanogenesis, and other secondary metabolites. BGS are classified based on several criteria, majorly based on substrate specificity, and nucleotide sequence identity (Henrissat and Davies, 1997). Plant BGS involved in hydrolysis of $\beta$-glucoside. BGS has a great potential to be used in various biotechnological processes like liberation of aromas, flavours, and isoflavone aglycones to oligosaccharides and alkylglycosides (Pyo et al., 2005; Yin et al., 2005; Otieno et al., 2006). In addition, microbial BGS has been reported to have the ability to transform plant glucoside isoflavones into aglycones, which is connected to cancer prevention, menopausal symptoms (Pyo et al., 2005),

\footnotetext{
* Corresponding Author

Bhagavathi Sundaram Sivamaruthi, Department of Pharmaceutical Sciences, Faculty of Pharmacy, Chiang Mai University, Chiang Mai 50200, Thailand. Email: sivasgene@gmail.com
}

inflammation and cardiovascular disease (Hu et al., 2009). BGS are present in many organelles and almost in all the living systems from bacteria to mammals with a variety of functionality. BGS are involved in the cellulolytic process of bacteria and fungi. The activity of enzyme is depends on length of the glucose chain and also participate in defense mechanism of plants and insects (Kubicek et al., 1993). BGS in yeasts, such as Debaryomyces hansenii, are responsible for the release of the flavoring compounds like nerol, geraniol, linalool, benzyl and phenylethyl alcohols (Rosi et al., 1994). Some of the yeast species were found in grapes with glycosidase activity such as Hanseniaspora, Pichia, Candida, Saccharomycodes, Metschnikowia, and Brettanomyces (Spagna et al., 2002). Delcroix et al. (1994) reported about presence of $\beta$-glucosidase activity in Saccharomyces cerevisiae and some recent studies suggested that fruits, such as apricot, fig, grapes, lychee, mangosteen, and papaya, are the best source of $S$. cerevisiae with BGS (Guimaraes et al., 2006; Maragatham and Panneerselvam, 2011; Khanda and Zainab, 2014). Moreover, BGS have various industrial applications as reviewed by Bhatia et al. (2002). Even though much detailed information on different BGS with distinct substrate specificity is available, several research units are intensively working about BGS to figure out the molecular aspects of their substrate specificity and assembly. The source of BGS also influences on their functionality. 
Several factors affect the BGS production, which can be optimized for the optimum production. One of the statistical and experimental designing approaches is a response surface methodology (RSM) (Xu et al., 2010).

The current investigation was conceived and carried out the screening, species identification, and cultural characterization of $S$. cerevisiae with BGS activity from Thai fruits and fruitderived beverages along with reference strains of $S$. cerevisiae. The impact of three variables like $\mathrm{pH}$, temperature, and concentration of sodium chloride was determined during BGS production by $S$. cerevisiae both in separate and combined manner (RSM).

\section{MATERIALS AND METHODS}

\section{Samples and isolation}

About 34 Thai fruits and fruit-derived beverages such as coconut, custard apple, durian, grapes, grape juices, sugarcane, lychee, lychee juices, mango, mangosteen, rambutan, and strawberry were collected from the local market, Chiang Mai, Thailand. Five $S$. cerevisiae strains were obtained from Thailand Institute of Scientific and Technological Research (TISTR), which were coded as TISTR 5003, TISTR 5024, TISTR 5051, TISTR 5059, and TISTR 5197. The yeast colonies were isolated as described earlier (Guimaraes et al., 2006).

\section{Biochemical and molecular identification}

The isolated yeast strains and the TISTR strains were inoculated in YPD and incubated at $30{ }^{\circ} \mathrm{C}$ for $12 \mathrm{~h}$. After incubation, yeast suspensions were prepared and adjusted to 0.2 $\mathrm{OD}$ at $600 \mathrm{~nm}$.

All the strains were assessed for D-glucose and galactose fermentation and growth in the presence of D-Ribose, D-Xylose and L-Rhamnose (Vaughan-Martini and Martini, 1993). The results of the biochemical test provide the information about the presence of $S$. cerevisiae in isolates. Then the suspected strain was confirmed through 5.8S rRNA based molecular identification. The nucleotide sequencing of an isolated strain was outsourced from KU-Vector Custom DNA Synthesis Service, Kasetsart University, Bangkok, Thailand.

The sequencing was carried out using the Big Dye Terminator Cycle Sequencing Kit and sequencing machine model ABI 377 (PE Applied Biosystem). The sequence analysis was performed using the BLASTN, National Centre for Biotechnology Information (NCBI) (http://blast.ncbi.nlm.nih.gov/ blast.cgi). The phylogenetic relationship between the deduced amino acid sequences was constructed by the neighbor-joining method.

\section{Determination of $\beta$-glucosidase activity}

The $\beta$-glucosidase activity was determined by measuring the rate of hydrolysis of $\rho$-nitrophenyl- $\beta$-d-glucopyranoside ( $\rho$ NPG, Sigma Chemical Co., Mo., USA) (Hernandez et al., 2003). The $\beta$-glucosidase activity was expressed as relative activity (\%).
Optimization of growth condition for maximum $\beta$-glucosidase production

Strains were inoculated in YPD broth with different $\mathrm{pH}$ range $(3.5,4.0,4.5,5.0,5.5$, and 6.0$)$ and incubated at $30^{\circ} \mathrm{C}$. The $\mathrm{pH}$ of the medium was adjusted using $50 \mathrm{mM}$ citrate phosphate buffer (Arroyo-Lopez et al., 2009). The another set of tubes were prepared with constant $\mathrm{pH}$, determined from previous assay, and incubated at different temperature ranging from 30 to $60{ }^{\circ} \mathrm{C}(30$, $40,45,50,55$, and $60^{\circ} \mathrm{C}$ ). The next set of tubes was prepared with constant $\mathrm{pH}$ and was incubated at predicted optimum temperature, but the concentration of $\mathrm{NaCl}$ in the medium was varied from 0.3 $-0.8 \%(\mathrm{w} / \mathrm{v})(0.3,0.4,0.5,0.6,0.7$, and 0.8$)$. All the tubes were incubated for $48 \mathrm{~h}$ and then supernatants were collected by centrifugation at $4{ }^{\circ} \mathrm{C}$ for $10 \mathrm{~min}$ at $5,000 \times g$ for the assessment of $\beta$-glucosidase activity.

\section{Optimization of growth condition by Response Surface Methodology (RSM)}

RSM was employed to optimize the multiple variants that influence the BGS activity. The Stat-Ease software (Design-Expert 6.0.2, Delaware, USA Echip, 2000-trail version) was used for experimental design and statistical analysis. A three-factor with three-level of Box-Behnken design was selected to evaluate the effect of combination of three independent variables such as $\mathrm{pH}$, temperature $\left({ }^{\circ} \mathrm{C}\right)$, and concentration of $\mathrm{NaCl}(\%$; w/v), coded as $\mathrm{X} 1, \mathrm{X} 2$ and $\mathrm{X} 3$, respectively. The values were selected from the individual assessment of the influence of selected variables. The minimum and maximum values for $\mathrm{pH}$, temperature, $\mathrm{NaCl}$ concentration were set as 3.5 and $4.5,30$ and $50{ }^{\circ} \mathrm{C}, 0.4$ and $0.6 \%$, respectively. The response values for reactive activity $(\%)$ of $\beta$ glucosidase were -1 (Lower), 0 (Middle), and +1 (Higher). The complete design consisted of 17 experimental sets including five replicates of the center point (WORAHARN et al. 2015). The reactive activity ( $\%$ ) of $\beta$-glucosidase produced from $S$. cerevisiae was statistically determined by actual response value. The Analysis of Variance (ANOVA) was used for data analysis and $p$ $<0.05$ was considered as significant. The experimental data were established by second-order polynomial regressed equations. Optimum parameters were defined by the Design-Expert software version 6.0.2.

\section{Kinetics study}

The optimum conditions for the maximum $\beta$-glucosidase activity were determined from the RSM. $\beta$-glucosidase activity was kinetically assessed to find out the optimum incubation time of selected strain to produce/ recover maximum enzyme activity. Strains were inoculated and incubated at the optimum condition for $48 \mathrm{~h}$ and samples were collected at different intervals $(0,1,3$, $6,9,12,24,36$, and 48). The samples were subjected to activity determination as detailed above.

\section{Statistical analysis}

Analysis of variance (ANOVA) with a confident interval of $95 \%(p<0.05)$ was reported, and all the experiments were 
performed in triplicates. The statistical program SPSS (version 17.0) was used for the analysis of significant differences in enzyme activity at a different temperature, $\mathrm{pH}$, sodium chloride concentration, and kinetic analysis.

\section{RESULTS AND DISCUSSION}

\section{Isolation and confirmation of yeast strain}

Samples were collected, and yeast cells were isolated. Isolated yeast cultures were biochemically tested such as ability to ferment d-glucose and galactose, and ability to grow in the presence of d-ribose, $\mathrm{d}$-xylose, and l-rhamnose, for predicting the species of the strain along with selected reference strains. The results of the biochemical tests and predicted species of the strains were tabulated (Table 1). There are four different strains were isolated and were predicted as Pichia spartinae, S. kluyveri, $P$. strasbergensis, and $S$. cerevisiae based on the biochemical profile. Strains $P$. spartinae and $S$. kluyveri were detected in three and five fruits samples respectively. $P$. strasbergensis and $S$. cerevisiae were isolated from only strawberry and sugarcane, respectively (Table 1). This data suggested that $S$. kluyveri is the most commonly resisting yeast strain of tested fruits at the time of sampling and analysis. Since, the objective of the investigation was to isolate $S$. cerevisiae, that particular strain (designated as HII31) was subjected to molecular-based confirmation by partial sequencing of 5.8S rRNA coding gene and phylogenetic analysis by the neighbor-joining method, and the results confirmed that strain as S. cerevisiae. The strain HII 31 has $100 \%$ similarity with S. cerevisiae strain W46. The strain was submitted to the NCBI GenBank database with the accession number of KC588952. The phylogenic tree of the selected strain HII31 is presented in Figure 1.

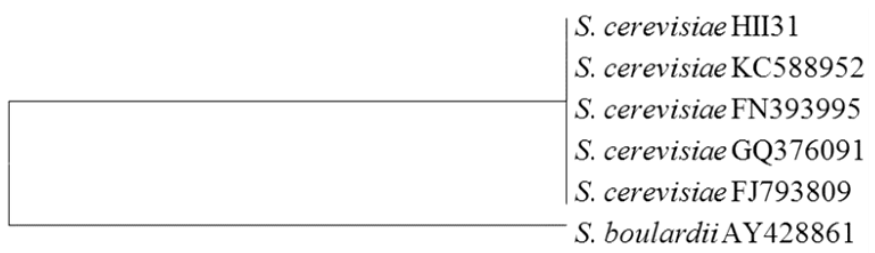

0.1

Fig. 1: Phylogenetic pattern of isolated S. cerevisiae HII31

\section{Optimization of enzyme production}

The production and release of any particular microbial enzyme are affected by several physical factors; most influential factors are $\mathrm{pH}$, temperature and salt concentration of the medium. Thus, the impact and influences of $\mathrm{pH}$, temperature, and $\mathrm{NaCl}$ concentration during BGS production has been studied in an independent manner and combined manner by BBD and RSM. Based on the previous reports (Spagna et al., 2002; Hernandez et al., 2003; Dhake and Patil, 2005) range of $\mathrm{pH}$, temperature and $\mathrm{NaCl}$ concentration were selected and tested by separate experiments. RSM is accepted and proved technique for the optimizing of multiple variables to achieve a maximum yield of desired products (Hajj et al., 2012).

Optimization of multiple variables for the maximum yield of BGS has been carried out by RSM and Box-Behnken design (BBD) of the experiment. Three levels (level codes -1, 0, 1) of three independent variables such as $\mathrm{pH}(\mathrm{X} 1)$, temperature (X2), and $\mathrm{NaCl}(\mathrm{X} 3)$, were selected in the current study. Influence of $\mathrm{pH}$ (3.5, 4.0, and 4.5), temperature $\left(30,40\right.$, and $\left.50{ }^{\circ} \mathrm{C}\right)$, and $\mathrm{NaCl}$ concentration $(0.4,0.5$, and $0.6 \%)$ on BGS production has been evaluated. Based on the RSM and BBD, seventeen experimental sets were designated and carried out. The predicted and actual values, represented as a relative activity, were represented in Table 2. The results suggested an increase in $\mathrm{pH}$, temperature, and $\mathrm{NaCl}$ concentration beyond the level of $4,40{ }^{\circ} \mathrm{C}$ and $0.5 \%$ affected the BGS activity, respectively. The optimum $\mathrm{pH}$, Temperature, and $\mathrm{NaCl}$ content of the medium for BGS activity by isolated $S$. cerevisiae was detected as $4,40{ }^{\circ} \mathrm{C}$ and $0.5 \%$ respectively (Figure $2 \mathrm{~A}, \mathrm{~B}, \mathrm{C})$. The optimum incubation period for the enzyme activity was $24 \mathrm{~h}$ (Figure 2D). Reports revealed that some cations have the ability to induce $\left(\mathrm{Na}^{+}\right.$and $\left.\mathrm{Ca}^{2+}\right)$ and inhibit $\mathrm{Cu}^{2+}$ and $\left.\mathrm{Mg}^{2+}\right)$ the BGS production (Chang et al., 2012). Moreover, presence of $\mathrm{Na}^{+}$ in the surrounding environment of yeast facilitates the effective BGS transport through membrane (Dhake and Patil, 2005). Thus the concentration of $\mathrm{NaCl}$ was also selected as one of the influencing factor of BGS production. The impact of selected three factors, $(\mathrm{pH}$, temperature, and $\mathrm{NaCl})$ on BGS activity has been evaluated by RSM. About seventeen experiments were executed to validate the predicted values of relative activity of BGS that was obtained by multiple regression analysis. The results suggested that both predicted and actual conditions for the maximum production of BGS, in terms of relative activity, were similar (Table 2). Some of the variations were observed in relative activity (\%) of BGS in individual experiments with same conditions, which are not statistically significant $(p>0.05)$. The response surface data like regression coefficient, $\mathrm{R}^{2}$ and probability values for the relative activity of BGS were obtained from Export Design Program V.6.0.2 and tabulated (Table 3).

Relative activity $(\%)=98.000+1.025 \times(\mathrm{X} 1)-0.130 \times(\mathrm{X} 2)+$ $0.570 \times(\mathrm{X} 3)-6.595 \times(\mathrm{X} 1)^{2}-6.170 \times(\mathrm{X} 2)^{2}-2.300 \times(\mathrm{X} 3)^{2}-$ Equation 1

Where $\mathrm{X} 1=\mathrm{pH}, \mathrm{X} 2=$ Temperature $\left({ }^{\circ} \mathrm{C}\right)$, and $\mathrm{X} 3=\% \mathrm{NaCl}$

The equation 1 shows the predicted quadratic polynomial model of BGS production. The coefficient of determination $\left(\mathrm{R}^{2}\right)$ was used for the checking of the predicted model under a numerical method. The maximum $\mathrm{R}^{2}(97.63 \%)$ and maximum adjusted $\mathrm{R}^{2}(96.21 \%)$ reveals that the model equation was adequate for predicting the maximum relative activity or maximum production of BGS by HII31. In general, the fitted model is described by lack-of-fit values for the variation in the experimental data (Trinh and Kang, 2010). For a successful experimental result, the lack-of-fit value should be statistically non-significant $(p>0.05)$. 
$\mathbf{A}$

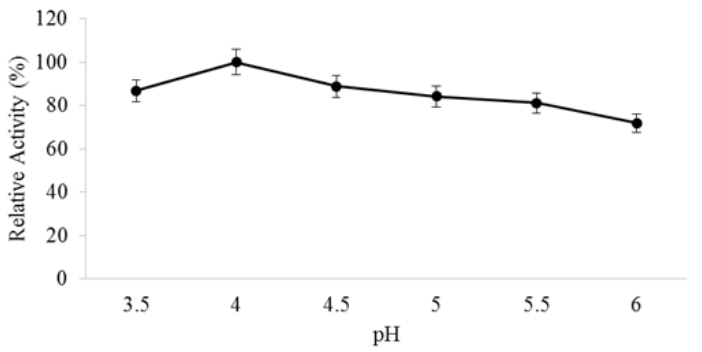

C

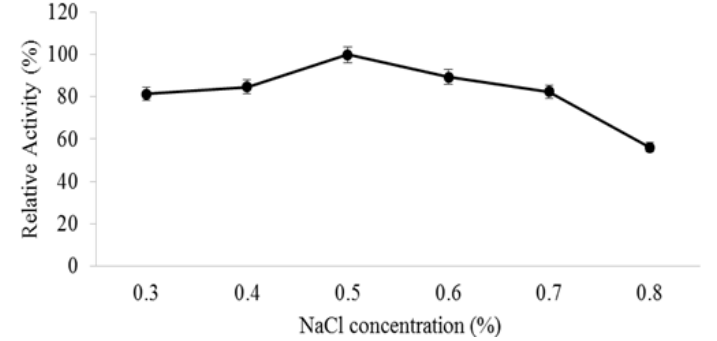

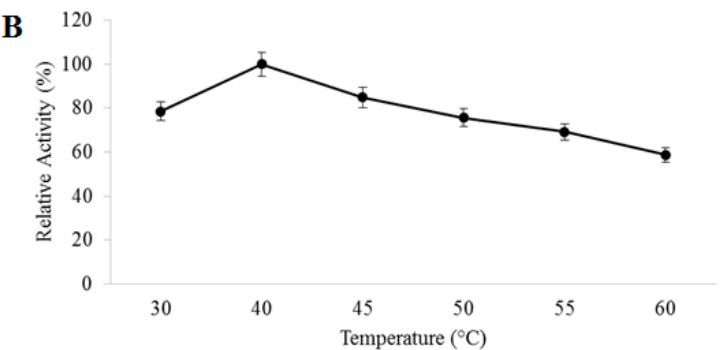

D $\quad 120$

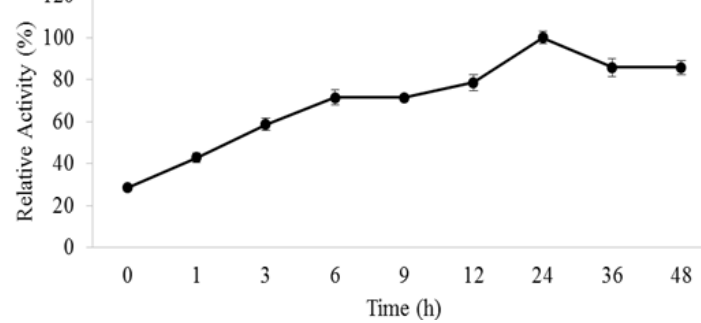

Fig. 2: The influence of $\mathrm{pH}(\mathrm{A})$, Temperature (B), $\mathrm{NaCl}$ concentration (C) of the medium, and incubation time (D) on BGS activity by S. cerevisiae HII31.

A

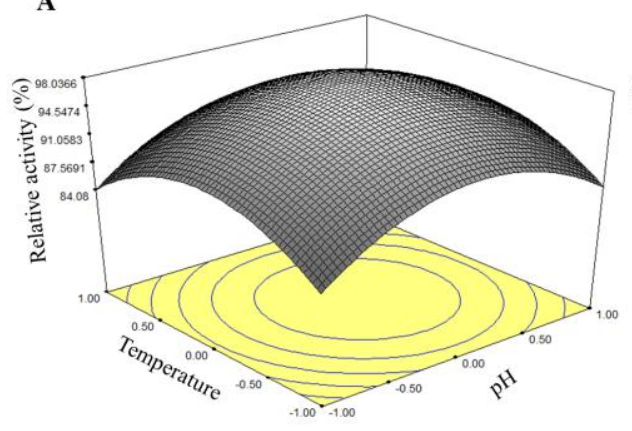

B

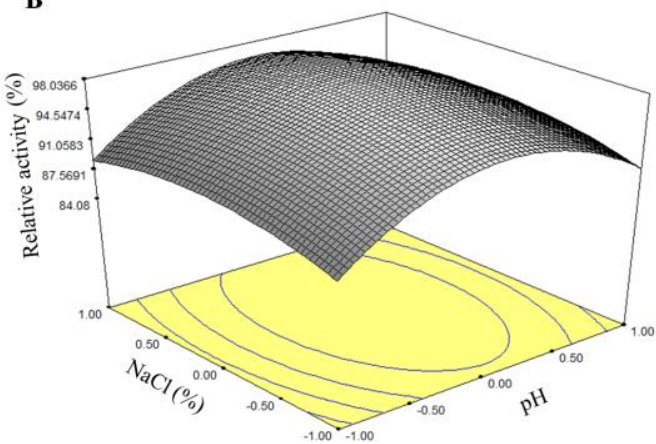

B

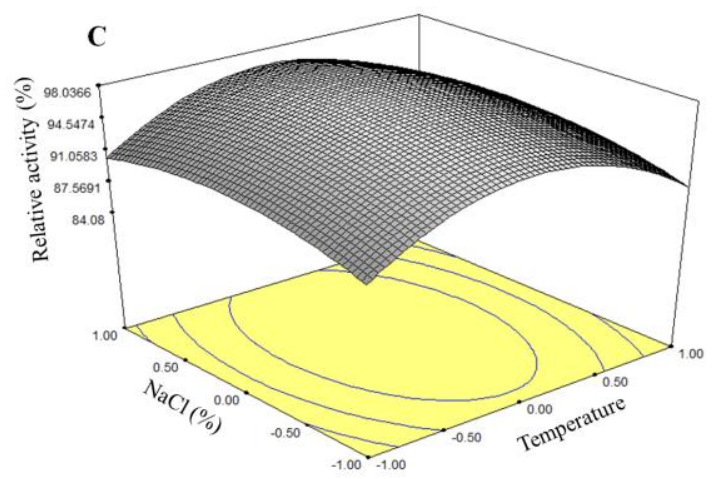

Fig. 3: Representation of response surface plots showing the influence of combined factors like $\mathrm{pH}$ and temperature (A), $\mathrm{pH}$ and $\mathrm{NaCl}$ concentration (B), temperature and $\mathrm{NaCl}$ concentration (C) on BGS activity by HII31.

The quadratic polynomial model for the \% relative activity of BGS and the variance analysis has been represented in Table 3. The linear parameters (X1) and quadratic parameters $\left(\mathrm{X}^{2}, \mathrm{X}^{2}\right)$ were found as significant at the level of $p<0.05$ and $p$ $<0.01$, respectively, and in all possibilities lack-of-fit was predicted as not significant $(p>0.05)$ (Table 4). These results are indicated that the relationship between response values and the independent variables were sufficient to represent the real optimal conditions for BGS activity by HII31. The response surface plots represented the optimum conditions such as $\mathrm{pH}$, temperature, and $\mathrm{NaCl}$ concentration for BGS activity by HII31 (Figure 3). The influence of $\mathrm{pH}$ and temperature on BGS activity with constant $\mathrm{NaCl}$ concentration $(0.5 \%)$ was predicted as 3.75 4.25 and $35-45^{\circ} \mathrm{C}$, respectively (Figure $3 \mathrm{~A}$ ). The influence of $\mathrm{pH}$ and $\mathrm{NaCl}$ concentration on BGS activity with the temperature at $40{ }^{\circ} \mathrm{C}$ was predicted as $3.75-4.25$ and $0.45-0.60 \%$, respectively(Figure 3B). The influence of temperature and $\mathrm{NaCl}$ concentration on BGS activity with constant $\mathrm{pH}$ of 4.0 was predicted as $35-45^{\circ} \mathrm{C}$ and $0.45-0.60 \%$, respectively (Fig. 3C). Whereas, BBD revealed that $\mathrm{pH} 4.0$, the temperature at $40^{\circ} \mathrm{C}$, and 
$0.5 \%$ of $\mathrm{NaCl}$ was the precise conditions for BGS activity (Table2). The influence of incubation time for the recovery of maximum enzyme activity by HII31 has been accessed along with reference strains. A study by Hernandez et al. (2003) on wine strain of $S$. cerevisiae for BGS activity suggested that optimal $\mathrm{pH}$ was 4 and the temperature ranging from $40-50{ }^{\circ} \mathrm{C}$. BGS produced by $S$. cerevisiae strain (AL 41), isolated from Sicilian must and wines, has been reported for the enzyme stability up to 35 days and it had optimum $\mathrm{pH}$ of 3.5-4.0 and temperature at $20{ }^{\circ} \mathrm{C}$
(Spagna et al., 2002). Whereas, in the present study, negative regulation of BGS production, in terms of relative activity, was noticed after $24 \mathrm{~h}$ of incubation, this might be resultant of utilization of BGS enzyme by yeast cells.

This phenomenon has not been observed in reference strains used in this study (Table 5). Thus further detailing is required in the form of scientific investigations to address the impact of incubation time on BGS production/activity by HII31.

Table 1: Source, biochemical test profile and growth of selected strains.

\begin{tabular}{|c|c|c|c|c|c|c|}
\hline \multirow{3}{*}{$\begin{array}{c}\text { Sources } \\
\text { (No. of strains) }\end{array}$} & \multicolumn{5}{|c|}{ Biochemical characterization } & \multirow{3}{*}{ Predicted as } \\
\hline & \multicolumn{2}{|c|}{ Fermentation of } & \multicolumn{3}{|c|}{ Growth in the presence of } & \\
\hline & D -glucose & Galactose & D-Ribose & D-Xylose & L-Rhamnose & \\
\hline Mangosteen (1) & + & - & - & - & - & Pichia spartinae \\
\hline Coconut (3) & + & + & - & - & - & Saccharomyces kluyveri \\
\hline Mango (5) & + & + & - & - & - & S. kluyveri \\
\hline Custard apple (2) & + & + & - & - & - & S. kluyveri \\
\hline Grapes and grape juices (5) & + & + & - & - & - & S. kluyveri \\
\hline Lychee and lychee juices (5) & + & - & - & - & - & P. spartinae \\
\hline Rambutan (5) & + & - & - & - & - & P. spartinae \\
\hline Strawberry (2) & + & $\mathrm{v}$ & $\mathrm{s}$ & + & - & Pichia strasbergensis \\
\hline Durian (1) & + & + & - & - & - & S. kluyveri \\
\hline Sugarcane (5) & + & $\mathrm{v}$ & - & - & - & S. cerevisiae \\
\hline TISTR 5003 & + & $\mathrm{v}$ & - & - & - & S. cerevisiae \\
\hline TISTR 5024 & + & $\mathrm{v}$ & - & - & - & S. cerevisiae \\
\hline TISTR 5051 & + & $\mathrm{v}$ & - & - & - & S. cerevisiae \\
\hline TISTR 5059 & + & $\mathrm{v}$ & - & - & - & S. cerevisiae \\
\hline TISTR 5197 & + & $\mathrm{v}$ & - & - & - & S. cerevisiae \\
\hline
\end{tabular}

+ : positive, - : negative, s: slow utilization, v: variable.

Table 2: The Box-Behnken design and experimental values of relative activity (\%) of $\beta$-glucosidase activity by $S$. cerevisiae.

\begin{tabular}{|c|c|c|c|c|c|}
\hline \multirow{2}{*}{ Run order } & \multicolumn{3}{|c|}{ Independent variables } & \multicolumn{2}{|c|}{ Relative activity (\%) } \\
\hline & pH (X1) & Temperature $\left({ }^{\circ} \mathrm{C}\right)(\mathrm{X} 2)$ & $\mathrm{NaCl}(\%)(\mathrm{X} 3)$ & Actual values & Predicted values \\
\hline 1 & 4.5 & 30 & 0.5 & 86.39 & 86.39 \\
\hline 2 & 4.0 & 50 & 0.4 & 88.83 & 88.83 \\
\hline 3 & 4.5 & 40 & 0.4 & 89.56 & 89.56 \\
\hline 4 & 3.5 & 30 & 0.5 & 84.34 & 84.34 \\
\hline 5 & 4.0 & 40 & 0.5 & $98.00^{\mathrm{a}}$ & 98.00 \\
\hline 6 & 4.0 & 30 & 0.4 & 89.09 & 89.09 \\
\hline 7 & 3.5 & 40 & 0.4 & 87.51 & 87.51 \\
\hline 8 & 3.5 & 50 & 0.5 & 84.08 & 84.08 \\
\hline 9 & 4.0 & 50 & 0.6 & 89.97 & 89.97 \\
\hline 10 & 3.5 & 40 & 0.6 & 88.65 & 88.65 \\
\hline 11 & 4.5 & 50 & 0.5 & 86.13 & 86.13 \\
\hline 12 & 4.0 & 40 & 0.5 & $97.00^{\mathrm{b}}$ & 98.00 \\
\hline 13 & 4.0 & 40 & 0.5 & $99.00^{\mathrm{c}}$ & 98.00 \\
\hline 14 & 4.0 & 30 & 0.6 & 90.23 & 90.23 \\
\hline 15 & 4.0 & 40 & 0.5 & $96.00^{\mathrm{d}}$ & 98.00 \\
\hline 16 & 4.0 & 40 & 0.5 & $100.00^{\mathrm{e}}$ & 98.00 \\
\hline 17 & 4.5 & 40 & 0.6 & 90.70 & 90.70 \\
\hline
\end{tabular}

a-e values are not significantly differ among the multiple experimental trails.

Table 3: Regression coefficients, $\mathrm{R}^{2}$, and probability values of response surface data for reactive activity (\%) of $\beta$-glucosidase.

\begin{tabular}{|c|c|c|c|c|}
\hline Term & Coefficient estimate & Standard error coefficient & Statistic value $(\mathrm{T})$ & $P($ Prob $>F)$ \\
\hline Constant & 98.00 & 0.45 & 217.78 & $<0.0001$ \\
\hline $\mathrm{pH}$ & 1.02 & 0.35 & 2.91 & 0.0159 \\
\hline Temperature $\left({ }^{\circ} \mathrm{C}\right)$ & -0.13 & 0.35 & -0.37 & 0.7208 \\
\hline $\mathrm{NaCl}(\%)$ & 0.57 & 0.35 & 1.63 & 0.1380 \\
\hline $\mathrm{pH} \times \mathrm{pH}$ & -6.59 & 0.49 & -13.45 & $<0.0001$ \\
\hline Temperature $\left({ }^{\circ} \mathrm{C}\right) \times$ Temperature $\left({ }^{\circ} \mathrm{C}\right)$ & -6.17 & 0.49 & -12.59 & $<0.0001$ \\
\hline $\mathrm{NaCl}(\%) \times \mathrm{NaCl}(\%)$ & -2.30 & 0.49 & -4.69 & 0.0008 \\
\hline
\end{tabular}

Standard deviation $=1.00, \mathrm{R}^{2}=97.63 \%$, Adjust $\mathrm{R}^{2}=96.21$. 
Table 4: Variance analysis of relative activity (\%) of $\beta$-glucosidase activity.

\begin{tabular}{lcccccc}
\hline Source & DF & Seq SS & Adj SS & Adj MS & $\boldsymbol{F}$ & \multicolumn{1}{c}{ P } \\
\hline Regression & 6 & 411.95 & 411.95 & 68.66 & 3.66 & 0.0001 \\
Linear & 3 & 11.14 & 11.14 & 3.71 & 121.90 & $<0.0001$ \\
Square & 3 & 365.69 & 365.69 & 121.90 & \\
Interaction & - & & & 1.00 & \\
Residual Error & 10 & 10.00 & 10.00 & 0.00 & 0.00 & \\
Lack-of-Fit & 6 & 0.00 & 0.00 & & \\
Pure Error & 4 & 10.00 & 10.00 & & \\
Total & 16 & 421.95 & & & \\
\hline
\end{tabular}

DF: Degree of freedom.

Table 5: $\beta$-glucosidase activity of $S$. cerevisiae strains.

\begin{tabular}{|c|c|c|c|c|c|c|}
\hline \multirow[t]{2}{*}{ Time (h) } & \multicolumn{6}{|c|}{ Relative activity (\%) } \\
\hline & HII31 & TISTR 5003 & TISTR 5024 & TISTR 5051 & TISTR 5059 & TISTR 5197 \\
\hline 0 & $28.57 \pm 1.43$ & $14.29 \pm 1.43$ & $42.86 \pm 2.14$ & $44.29 \pm 2.21$ & $32.86 \pm 1.64$ & $14.29 \pm 0.71$ \\
\hline 1 & $42.86 \pm 2.14$ & $15.71 \pm 1.57$ & $45.71 \pm 2.29$ & $28.57 \pm 1.43$ & $35.71 \pm 1.79$ & $21.43 \pm 1.07$ \\
\hline 3 & $58.57 \pm 2.93$ & $17.14 \pm 1.71$ & $47.14 \pm 2.36$ & $42.86 \pm 2.14$ & $38.57 \pm 1.93$ & $28.57 \pm 1.43$ \\
\hline 6 & $71.43 \pm 3.57$ & $18.57 \pm 1.86$ & $50.00 \pm 2.50$ & $35.71 \pm 1.79$ & $42.86 \pm 2.14$ & $40.00 \pm 2.00$ \\
\hline 9 & $71.43 \pm 3.57$ & $21.43 \pm 2.14$ & $52.86 \pm 2.64$ & $60.00 \pm 3.00$ & $50.00 \pm 2.50$ & $40.00 \pm 2.00$ \\
\hline 12 & $78.57 \pm 3.93$ & $20.00 \pm 2.00$ & $65.71 \pm 3.29$ & $71.43 \pm 3.57$ & $42.86 \pm 2.14$ & $50.00 \pm 2.50$ \\
\hline 24 & $100.00 \pm 5.00^{* \#}$ & $54.29 \pm 2.71$ & $70.00 \pm 3.50$ & $64.29 \pm 3.21$ & $54.29 \pm 2.71$ & $60.00 \pm 3.00$ \\
\hline 36 & $85.71 \pm 4.29$ & $78.57 \pm 3.93 *$ & $92.86 \pm 4.64^{\#}$ & $78.57 \pm 3.93^{*}$ & $60.00 \pm 3.00$ & $71.43 \pm 3.57$ \\
\hline 48 & $85.71 \pm 4.29$ & $77.14 \pm 3.86$ & $92.86 \pm 3.94$ & $71.43 \pm 3.57$ & $64.29 \pm 3.21 *$ & $72.86 \pm 3.64 *$ \\
\hline
\end{tabular}

* Significant value $(p<0.05)$ with other strains; ${ }^{\#}$ Non-significant value $(p>0.05)$

\section{CONCLUSION}

The current study established and revealed the isolation, identification of BGS producing S. cerevisiae strain (HII31) from Thai fruit-derived beverages and culture conditions for the maximum production of BGS. Further meticulous research on enzyme recovery and purification will unbolt the way to attain high quality safe microbial enzyme with industrial and pharmaceutical demands. The selected high potential strain with $\beta$ glucosidase activity will be used as starter culture for plant-derived food biotransformation in near future.

\section{ACKNOWLEDGMENTS}

BSS acknowledge the support received from Chiang Mai University through CMU-Post Doctoral research fellowship. We also gratefully acknowledge to the Faculty of Pharmacy and Chiang Mai University, Chiang Mai, Thailand.

\section{DECLARATION}

Screening and isolation part of the study was performed at Health Innovation Institute, Chiang Mai, Thailand and the identified strain is belongs to Health Innovation Institute. The RSM studies were carried out at Faculty of Pharmacy, Chiang Mai University.

\section{REFERENCES}

Arroyo-Lopez FN, Orlic S, Querol A, Barrio E. Effects of temperature, $\mathrm{pH}$ and sugar concentration on the growth parameters of Saccharomyces cerevisiae, S. kudriavzevii and their interspecific hybrid. Int J Food Microbiol, 2009; 131: 120-127.

Bhatia Y, Mishra S, Bisaria VS. Microbial beta-glucosidases: cloning, properties, and applications. Crit Rev Biotechnol, 2002; 22: $375-$ 407.
Chang KH, Jo MN, Kim KT, Paik HD. Purification and Characterization of a Ginsenoside $\mathrm{Rb}$ (1)-Hydrolyzing beta-Glucosidase from Aspergillus niger KCCM 11239. Int J Mol Sci, 2012; 13: 1214012152.

Delcroix A, Günata Z, Sapis JC, Salmon JM, Bayonove C. Glycosidase Activities of Three Enological Yeast Strains During Winemaking: Effect on the Terpenol Content of Muscat Wine. Am J Enol Vitic, 1994; 45: 291-296.

Dhake AB and Patil MB. Production of B-Glucosidase by Penicillium purpurogenum. Braz J Microbiol, 2005; 36: 170-176.

Guimarães TM, Moriel DG, Machado IP, Picheth CMTF, Bonfim TMB. Isolation and characterization of Saccharomyces cerevisiae strains of winery interest. Braz J of Pharm Sci, 2006; 42: 119-126.

Hajj Y, Louka N, Nguyen C, Maroun R. Low Cost Process for Phenolic Compounds Extraction from Cabernet Sauvignon Grapes (Vitis vinifera L. cv. Cabernet Sauvignon). Optimization by Response Surface Methodology. Food Nutr Sci, 2012; 3: 89-103.

Henrissat B and Davies G. Structural and sequence-based classification of glycoside hydrolases. Cur Opin Strut Biol, 1997; 7: 637644.

Hernandez LF, Espinosa JC, Fernandez-Gonzalez M, Briones A. Beta-glucosidase activity in a Saccharomyces cerevisiae wine strain. Int J Food Microbiol, 2003; 80: 171-176.

Hu SC, Hong K, Song YC, Liu JY, Tan RX. Biotransformation of soybean isoflavones by a marine Streptomyces sp 060524 and cytotoxicity of the products. World J Microbiol Biotechnol, 2009; 25: 115 121.

Khanda OK, Zainab MALZ. Isolation and Identification of Saccharomyces cerevisiae var boulardii and its Uses as a Probiotic (in vitro). Rafidain J Sci, 2014; 25: 1-11.

Kubicek CP, Messner R, Gruber F, Mach RL, Kubicek-Pranz EM. The Trichoderma cellulase regulatory puzzle: from the interior life of a secretory fungus. Enzyme Microb Technol, 1993; 15: 9099.

Maragatham C and Panneerselvam A. Isolation, identification and characterization of wine yeast from rotten papaya fruits for wine production. Adv Applied Sci Research, 2011; 2: 93-98.

Otieno DO, Ashton JF, Shah NP. Evaluation of enzymic potential for biotransformation of isoflavone phytoestrogen in soymilk by Bifidobacterium animalis, Lactobacillus acidophilus and Lactobacillus casei. Food Res Int, 2006; 39: 394-407. 
Pyo YH, Lee TC, Lee YC. Enrichment of bioactive isoflavones in soymilk fermented with beta-glucosidase-producing lactic acid bacteria. Food Res Int, 2005; 38: 551-559.

Rosi I, Vinella M, Domizio P. Characterization of betaglucosidase activity in yeasts of oenological origin. J Appl Bacteriol, 1994; 77: 519-527.

Spagna G, Barbagallo RN, Palmeri R, Restuccia C, Giudici P. Properties of endogenous beta-glucosidase of a Saccharomyces cerevisiae strain isolated from Sicilian musts and wines. Enzyme Microb Technol, 2002; 31: 1030-1035.

Trinh TK and Kang LS. Application of Response Surface Method as an Experimental Design to Optimize Coagulation Tests. Environ Eng Res, 2010; 15: 63-70.

Vaughan-Martini A and Martini A. A Taxonomic Key for the Genus Saccharomyces. Syst Appl Microbiol, 1993; 16: 113-119.

Woraharn S, Lailerd N, Sivamaruthi BS, Wangcharoen W, Sirisattha S, Peerajan S, Chaiyasut C. Evaluation of factors that influence the L-glutamic and $\gamma$-aminobutyric acid production during Hericium erinaceus fermentation by lactic acid bacteria. Cyta-J Food, 2016; 14: $47-$ 54
Xu R, Ma S, Wang Y, Liu L, Li P. Screening, identification and statistic optimization of a novel exopolysaccharide producing Lactobacillus paracasei HCT. Afr J Microbiol Res, 2010; 4: 783-795.

Yin LJ, Li LT, Liu H, Saito M, Tatsumi E. Effects of fermentation temperature on the content and composition of isoflavones and beta-glucosidase activity in sufu. Biosci Biotechnol Biochem, 2005; 69: $267-272$

\section{How to cite this article:}

Sirilun S, Chaiyavat C, Pengkumsri N, Peerajan S, Chaiyasut K, Suwannalert P, Sivamaruthi BS. Screening and characterization of $\beta$-glucosidase production by Saccharomyces cerevisiae. J App Pharm Sci, 2016; 6 (05): 029-035. 